\title{
The Research of Design Based on Social Commerce
}

\author{
Juhua $\mathrm{Wu}^{1}$, Meng $\mathrm{Xu}^{1}$, Zan $\mathrm{Mo}^{1}$, Luo Liao ${ }^{1}$ \\ ${ }^{1}$ School of Management, Guangdong University of Technology, Guangzhou, China. \\ Correspondence: Meng Xu, School of Management, Guangdong University of Technology, Guangzhou 510520, China
}

Received: May 27, 2015

Accepted: June 10, 2015

Available online: June 29, 2015

doi:10.11114/ijsss.v3i4.916

URL: http://dx.doi.org/10.11114/ijsss.v3i4.916

\begin{abstract}
Based on previous design theories which focus only on artifacts, we study the factors of social commerce design with application environment and human capabilities. By comparing social commerce design model and information model, we develop a new social commerce design model, further exploring user requirements after shopping, including the exploration of brand community, sharing offline social shopping experience and the improvement of user social skills. According to the new model, we revealed the common features of social commerce design, including the individual, conversation, community, commerce and management levels. Besides, this paper pointed out social commerce design research problems in future.
\end{abstract}

Keywords: social commerce, design science, social features, user requirement

\section{Introduction}

With the spread of Web 2.0 and social media, user behavior starts change from passive access to information to actively create and disseminate information, leading to the emergence of a new online business - social commerce. As a an Internet-based commercial application, social commerce is taking advantage of social media and Web 2.0 technologies to support social interaction and user generated content(UGC) to help consumers make decisions and obtain products and services within online marketplaces and communities.

In the social commerce environment, before making purchase decision users usually search relevant information on the internet. A report by Tamba indicates that $76 \%$ of people rely on recommendations from friends to inform their purchases, only $15 \%$ rely on advertising. According to the report of we are social, active social network users of China reach 623300000 , social media users who spent average time of 90 minutes on platform every day account for $42 \%$ of the population. According to the survey of Socialbeta, $91 \%$ of people will go to store because of online experience, $89 \%$ of people use search engine to investigate information, $62 \%$ of people will go to store to complete purchase decision after online survey, $72 \%$ of consumers trust product evaluation on the network similar with friends recommended, $78 \%$ of consumers argue that social media posts will affect their buying decisions. These numbers suggest that users receive and diffuse brand information on social networking sites, and then affect their buying behavior, which have become an important part of everyday life.

Based of catalog design, traditional electronic commerce focusing on transaction and maximize efficiency more than users only pays attention to one-way browsing, where information from user is rarely sent back to businesses or other users. Therefore, traditional electronic commerce design concentrates more on usefulness, information quality, system quality and service quality. However, social commerce focus is not only shopping and trading volume, which is oriented from the pursuit of real-time transactions to sustained profitability, from shopping to social networking or entertainment. Social commerce is also oriented toward two-way communication that allows customers express themselves and share their information with other customers as well as with businesses, and communication between groups form crowdsourcing. Along with the characteristic of social commerce changes, design features of social commerce have also changed.

\section{Design framework of Social Commerce}

Early design theory contended that design is both a process and a product. Simon (1996) deems that design theory involves fulfilling a task by designing artifact. Artifact, including architecture, model, method and example, lacks of detailed description of design knowledge. However, artifacts, to some extent, can be reasoned its structure and function. Hevner et al. (2004) argues that design is a process of the assessment, and the goal is to produce a set of artifacts by 
defining and developing artifacts to support adaptability of the user interface. In information system, design science research involves the construction of a wide range of socio-technical artifacts. Academic studies usually touched on the realization of the artifact rather than focused on application environment of design. However, based on previous design theory, Gregor and Hevner (2013) proposed design research framework to highlight the factors affecting design science from environment and people perspectives.

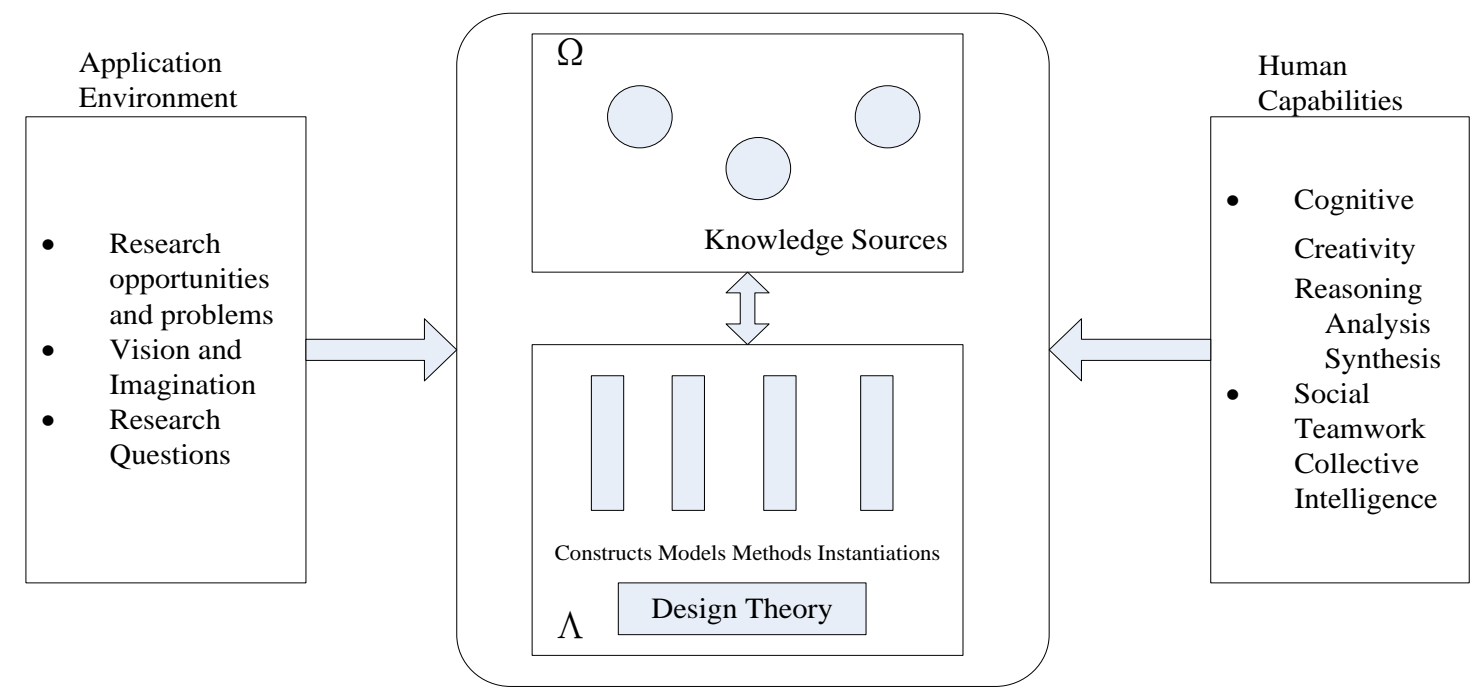

Figure1. Design Science Research Framework

Design science research begins with an important opportunity, challenging problem, or insightful vision for something innovative in the application environment. Research questions typically center on how to increase some measure of operational utility with new or improved design artifacts. The new design research contribution is an important extension of an existing artifact or the application of an existing artifact in a new application domain. As an evolution of e-commerce, platform design of social commerce has changed too. Different from traditional e-commerce enterprises through unified electric business platform entrance, social commerce is a multi-channel integration platform, where users directly into web site via two-dimension code, search engines, community platform, leading to diversification of information transmission. Therefore, design should emphasis interface, with various channels integrated with platform, which will encourage and restrain user behavior. Regarding network structure, traditional e-commerce emphasizes user shopping process and communication between user and merchant, while social commerce emphasizes user strong/weak relationship and exchange of information between users, contributing to untangle social processes that enable and constrain the diffusion of behaviors in society. Therefore, design should focus on communication and depth to optimize communication between users.

The success of a design research is predicated on the research skills of the team in appropriately drawing knowledge from both $\Omega$ and $\Lambda$ bases to ground and position the research; the teams' cognitive skills in designing innovative solutions; and the teams' social skills in bringing together all of the individual members' collective intelligence via effective teamwork. In the social commerce environment, cognitive ability, creativity and collective intelligence have changed.

With regard to cognition, with the development of web technology, asymmetry of information has reduced and user's cognitive ability has enhanced. Cognitive processes may be distributed in three ways. First, individuals in a group actively organize themselves and coordinate their efforts to accomplish tasks. Their rich interactions give rise to a complex system with user cognitive processes, which increases difficulty of design. Second, user cognitive properties distinct from those of artifacts components and cognitive processes of user work environment, referred to as embodied or structural cognition. Third, there is a temporal aspect of distributed cognition that suggests that experience from past cognitive events can have a bearing on subsequent ones. The improvement of user cognitive results in transparency design of social commerce and user feedback function optimization which mainly promotes feedback between users and platforms.

In terms of creativity, based on design recommendation via online survey, users participate in online product design. Social commerce design should strengthen users' control abilities, give users design permission and construct ecological system for users.

On collective intelligence, due to the influence of social media to the user, cluster consumers come into being. Users 
show personal wisdom via social media and cooperate with other users to create collective intelligence. Besides as information receiver and selectors, users play the role of social group who use information to accomplish activities. Therefore, social commerce design should dig into user requirement, meet demand of social group and improve social activities.

\section{Design Features of Social Commerce}

The expression social commerce is first introduced in 2005 on Yahoo! Soon, major Internet companies began to make user participation as a way to increase business value, leading to rapid development of social commerce. Due to the development of theory which is promoted from practice, Zhang and Benjamin (2007) constructed information model, in the perspective of software developers, which consists of four components: information, technology, people, and organization. But there are some limitations in integrating information and technology components. Huang and Benyoucef (2013) putted forward social commerce design model, in the perspective of technical, from individual, conversation, community, commerce four aspects progressively described social commerce platform design. But there is no further study potential demand of users after shopping. Combining with advantages and disadvantages of these two models, this paper put forward a new social commerce design model.

\subsection{Design Model}

Zhang and Benjamin (2007) proposed information model, including information, technology, people, and organization, see table 2. On the information aspect, the general trend is to move from peer production to social production, consumers and businesses produce together, global crowdsourcing. On the technology aspect, platform and function extended beyond blog to include social network, media sharing site, SaaS, local service and smartphone. On the organization aspect, business strategy shifted from short-tail thinking to long-tail thinking, such as brand social network, small ecological social network and niche brand. On the people aspect, human social attribute evolved from a general description to multi-dimensional exploration, such as social psychology and financial situation.

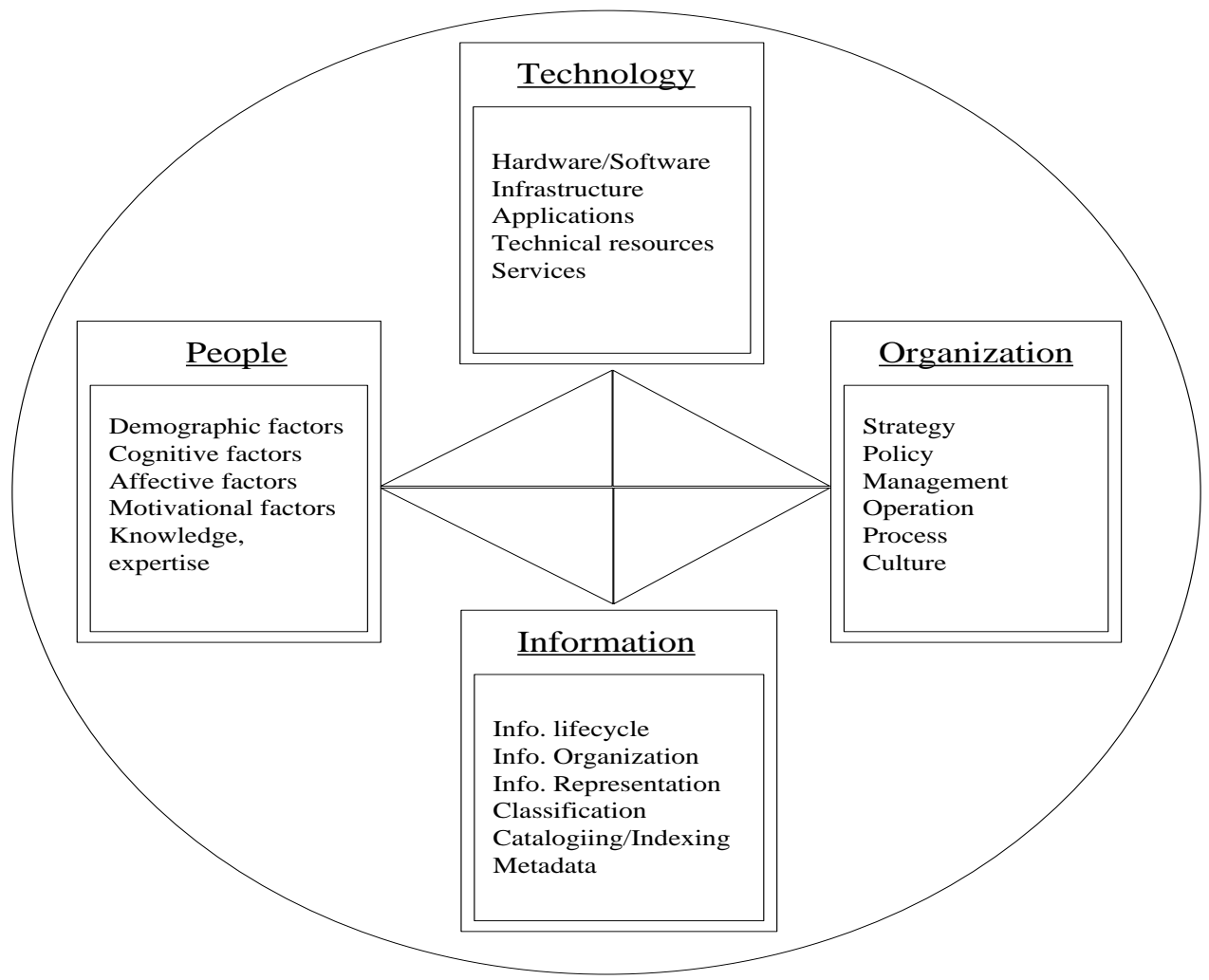

Figure 2. Information Model

Zhang and Benjamin (2007) putted forward social commerce design model, which is divided into four major layers: individual, conversation, community and commerce, see table 2. Individual layer is where all the information starts, including user profiles and user generated content. Conversation layer is where individuals express themselves through postings and exchanges with other individuals, including individual layer. A community is created or consolidated through interactions, including conversation layer. Commerce layer do commerce by leveraging relationships that exist 
between members of a community, including community layer. Yet, the key distinction between e-commerce and social commerce is clear in that e-commerce contains individual and commerce layer. Social commerce, on the other hand, contains these four layers.

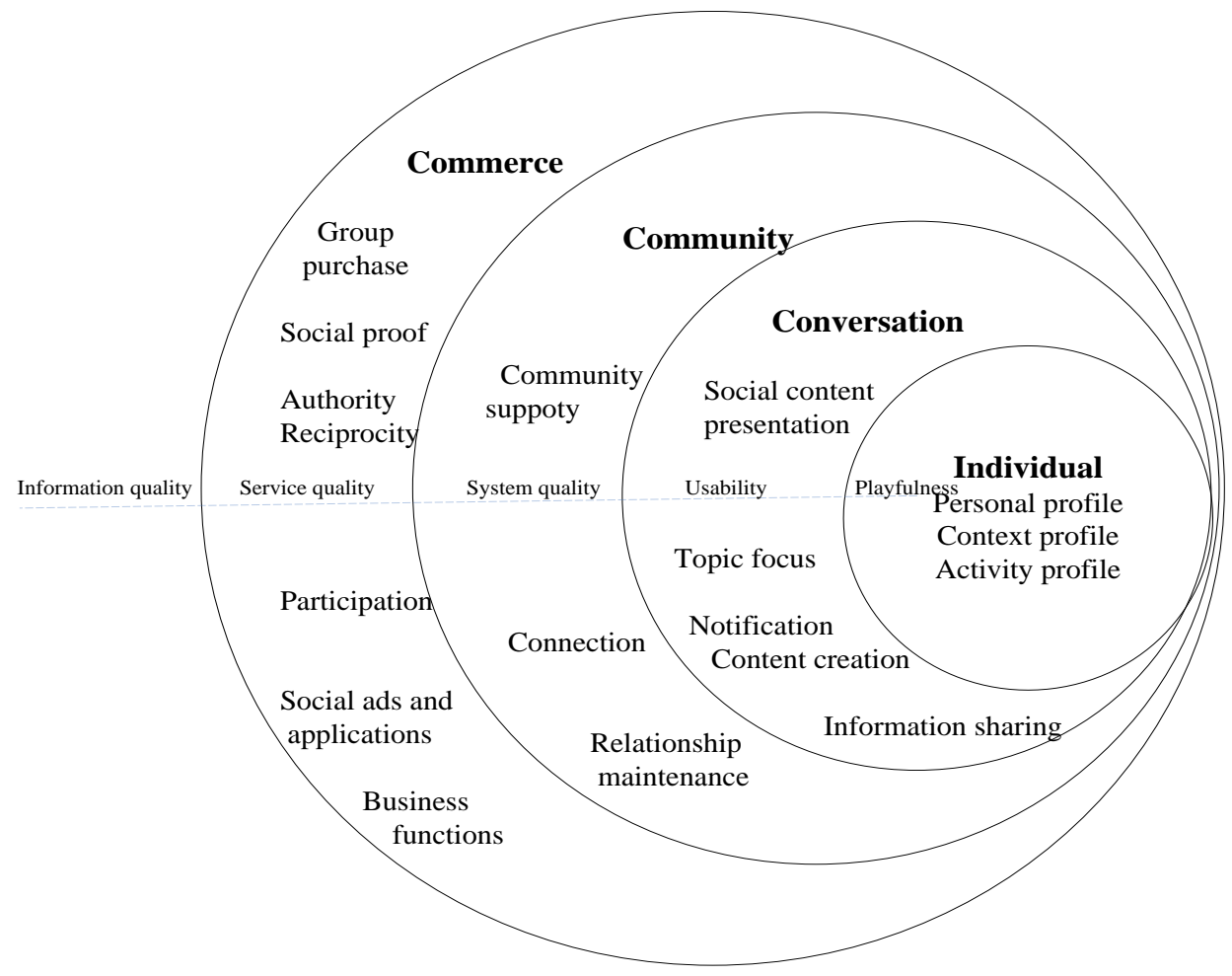

Figure 3. Social Commerce Design Model

The comparison between social commerce design model and information model follows, as shown in table 1 .

Table 1. The Advantages And Disadvantages of Two Models

\begin{tabular}{|c|c|c|}
\hline & advantages & disadvantages \\
\hline $\begin{array}{l}\text { information } \\
\text { model }\end{array}$ & $\begin{array}{l}\text { Contribute to enterprise strategic } \\
\text { positioning and market positioning. } \\
\text { Provide a useful integration framework } \\
\text { to help empirical researchers test theory, } \\
\text { design and develop artifacts. } \\
\text { Better understanding of some social } \\
\text { factors that need to explain and predict } \\
\text { sustainable demand of social commerce. }\end{array}$ & $\begin{array}{l}\text { The correspondence between model } \\
\text { and implementation is not strong. } \\
\text { These components are } \\
\text { interdependent in most business and } \\
\text { organizational settings. } \\
\text { Social commerce economic } \\
\text { performance and management } \\
\text { ability between strategic positioning } \\
\text { and design elements are difficult to } \\
\text { match. }\end{array}$ \\
\hline $\begin{array}{l}\text { social } \\
\text { commerce } \\
\text { design } \\
\text { model }\end{array}$ & $\begin{array}{l}\text { Combined with e-commerce and Web } \\
2.0 \text { design features, the model can be } \\
\text { used to guide social commerce platform } \\
\text { design. } \\
\text { The model highlights technical design in } \\
\text { connection with information model. } \\
\text { The model emphasizes the common } \\
\text { value of information across all the layers } \\
\text { of social commerce design and the core } \\
\text { value of people. }\end{array}$ & $\begin{array}{l}\text { Model and related design need to be } \\
\text { further validated in practice. } \\
\text { The model doesn't identify patterns } \\
\text { of social commerce from a software } \\
\text { engineering perspective. } \\
\text { Lack of synthesize design principles } \\
\text { between e-commerce-based and } \\
\text { social network based social } \\
\text { commerce platforms. }\end{array}$ \\
\hline
\end{tabular}


Based on the above analysis, we combining information model improve social commerce design model which only from technology dimension design by adding from management dimension design. Then we put forward a new social commerce design model, namely individual, conversation, community, commerce, with a management layer, see figure 4.

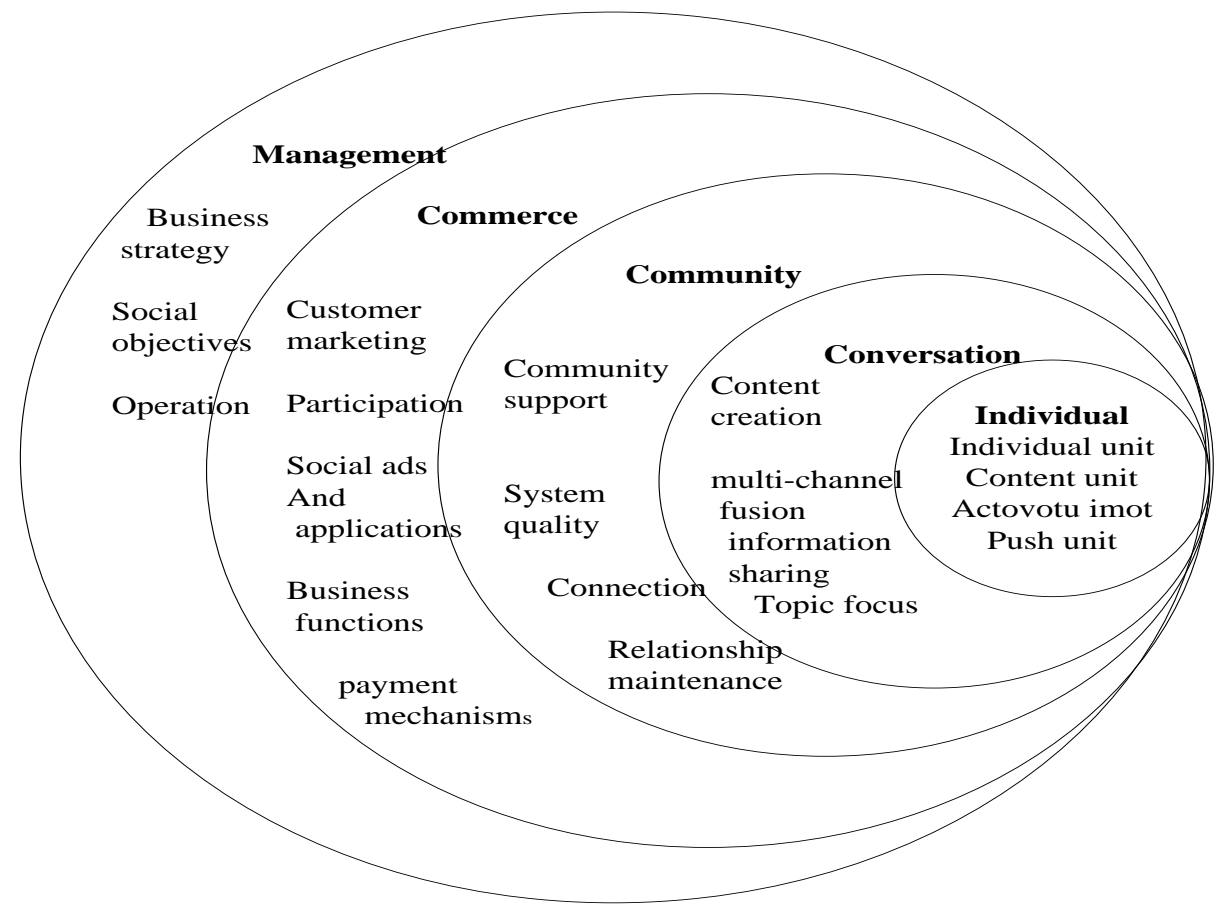

Figure 4. New Social Commerce Design Model

Individual is the first layer, where all the information starts, including user profiles as well as user generated content and the key is to generate information. Social commerce design model puts forward personal profile contributed to identify participants, content profile contributed to seek information and activity profile contributed to encourage users to participate in activities. According to individual dimension of information model, we argue that all the home page can be refined to individual unit reflected user demographic factors, content unit reflected user knowledge and influence factors, activity unit reflected users cognitive factors, push unit reflected user motivation factors. User could leverage like, comment, publish and share tools to generate content which shows user's knowledge and experience by individual unit, content unit and activity unit. This paper adds push unit to display other user footprint and advertisement contributed to analysis of motivation factors of users to participate in social activities or shopping.

Conversation is the second layer, where user communicates with other users via social tools to represent himself, further leading to the spread of UGC and collective intelligence, including individual layer, and the key is to diffuse information. Social commerce design model puts forward content creation, social content presentation, information sharing, topic focus, notification, providing participants with many interactive features to create a community. Content creation only involves encouraging user feedback and share information. Regarding enterprises generate content, we extend characteristics of content creation. Social content presentation refers to information dissemination way and format diversification, while we mainly consider the problem of designing multi-channel fusion of information dissemination. Information sharing is convenient for user to active query information; notification refers to that updated information automatic transfers to friends via social tools, which makes friends passive receive information. We extract information sharing, including users active and passive access to information. Therefore, features of conversation layer are summarized as content creation, multi-channel fusion, information sharing, topic focus.

Community is the third layer, where community is created by interaction, including conversation layer and the key is to maintenance information. Social commerce design model puts forward community support, connection and relationship maintenance. Community support contains information support and technical support. Regarding emotional support, we extend characteristics of community support. Relationship maintenance focus on relationship between users and relationship between users and community, ignoring relationship between users and merchants, then we extend characteristics of relationship maintenance. In addition, we consider system quality characteristics of community layer horizontal line, including system interaction and user control which improve interaction mechanism between users and 
enterprises. Therefore, features of community layer are summarized as community support, system quality, connection and relationship maintenance.

Commerce is the fourth layer, where merchants are allowed to do business in the established community, including community layer and the key is to leverage information. Social commerce design model puts forward group, social proof, authority, reciprocity, participation, social ads and applications, business functions, ordering function and payment mechanisms. Ordering function refers to encourage user to participate in the brand network applications, which considers user utility requirements far more than hedonic requirements. Then, we extend ordering function characteristics. We believe that group, social proof, authority and reciprocity aim to utilize user psychological to solve user shopping uncertainty in advance, which can be refined customer marketing. Participation, social ads and applications and business functions aim to meet demands of users' shopping. Payment mechanisms refer to shopping payment. Therefore, features of community layer are summarized as customer marketing, participation, social ads and applications, business functions and payment mechanisms.

Management is the fifth layer, which refers to latent demand after that users and merchants collaborate to do business, including commerce layer and the key is to manage information. After shopping, user shares shopping experience in the online community, further extends to offline. Therefore, enterprise should dig into user latent demand. Combining with organization dimension of information model, we should strengthen design of management level, including business strategy, social objectives and operation. Business strategy, we should shift from short-tail thinking to long-tail thinking, from transaction to brand, subdivide user community and explore niche brand community to find niche products. Social objectives, we focus move from economic development problems (e.g. corporate profit, business scale, enterprise rating) to outcomes of social and economic significance (e.g. job placement, productivity, innovation, health), promote the sustainable development of social commerce. Operation, online business should shift to O2O.

\subsection{Design Feature}

Base on the new social commerce design model, we summarize common design features throughout the five layers, including individual, conversation, community, commerce and management, as shown in table 2.

Table 2 The common design features of social commerce

\begin{tabular}{|c|c|}
\hline$\underset{\text { prir }}{\text { De }}$ & is \\
\hline Indivic & $\begin{array}{l}\text { Individual unit, which focus on user basic information, such as name, sex, } \\
\text { photo, etc. } \\
\text { Content unit, which focus on information about affecting user participate in } \\
\text { activities or shopping, such as interesting knowledge recommended. } \\
\text { - Activity unit, which focus on user cognitive ability, provide user-friendly and } \\
\text { structured interface to motivate user to get involved in activities. } \\
\text { - Push unit, which focus on the motivation of participants, such as user } \\
\text { psychological gender to explore brain sex is more male or female. }\end{array}$ \\
\hline Conv & $\begin{array}{l}\text { - Content creation. First, user generate content, user not only listen, look and } \\
\text { touch social content, but also generate content directly generated by user in an } \\
\text { active way by rate tag or write reviews or in a passive way by customers } \\
\text { behavior. Second, enterprise generate content, such as transplantation of } \\
\text { product information in social activities. } \\
\text { - Multi-channel fusion, which refers to offer rich information, such as micro } \\
\text { letter, weibo, plug-ins, etc. Meanwhile, user-friendly website interface should } \\
\text { be provided. } \\
\text { - Information sharing, which provides companies with strategy information for } \\
\text { projecting and anticipating trends. On the other hand, users' updated } \\
\text { information will be automatically delivered to friends via social tools. } \\
\text { - Topic focus, which allows user to organize topics via social tools to closely } \\
\text { interact with other users. }\end{array}$ \\
\hline Comr & $\begin{array}{l}\text { - Community support, which provides real time community support, including } \\
\text { emotional support, information support and technical support. Emotional } \\
\text { support, user could perceive care, love and support of members of a group, }\end{array}$ \\
\hline
\end{tabular}




\begin{tabular}{|c|c|c|}
\hline & • & $\begin{array}{l}\text { which increased users' trust and satisfaction, leading them to use communities } \\
\text { and other social platforms when buying a product or service. Information } \\
\text { support, user could receive information generated from enterprises or other } \\
\text { users to overcome the uncertainty of decision. Technical support, user could } \\
\text { receive technical help from other members of communities. } \\
\text { System quality. First, system interaction which provided more social, } \\
\text { interactive and collaborative online experience, gathered individual } \\
\text { intelligence to answer questions. Second, participant control which allowed } \\
\text { users to control over the data that they provide for services and applications. } \\
\text { Connection, user could link with attractive people to build social bonds and } \\
\text { trust. } \\
\text { Relationship maintenance, which provides social activities for participants to } \\
\text { increase feelings between users and communities, feelings between users and } \\
\text { merchants, feelings between users. Meanwhile, follow up and feedback } \\
\text { services are provided to support service improvement. }\end{array}$ \\
\hline Commerce & • & $\begin{array}{l}\text { Customer marketing. First, group purchase to link with people who have } \\
\text { similar shopping interests to create group customers shopping lists which } \\
\text { usually have better results. Second, social proof provided similar consumer } \\
\text { shopping information. Third, authority presented expert recommendations to } \\
\text { resolve customer uncertainty about what to buy. Forth, reciprocity enabled } \\
\text { participants to receive rewards, such as monetary or non-monetary via } \\
\text { clicking share or like button. } \\
\text { Participation, which encourages customers participate in the process of } \\
\text { product design and development, editing, evaluating and submitting design } \\
\text { ideas. } \\
\text { Social ads and applications. First, advertising services and applications are } \\
\text { provided. Second, advertising information is transplanted in social activities. } \\
\text { Third, third-party social networking services are integrated as word of mouth } \\
\text { marketing. } \\
\text { Business functions. First, ordering mechanism provides order status query } \\
\text { services. Second, shopping experience not only meet the demand of user } \\
\text { utility, but also meet the demand of users of pleasure, such as curious, } \\
\text { interesting, and creativity, etc. Compared to utilitarian motivation, hedonic } \\
\text { motives influence user participation behavior over browsing behavior. } \\
\text { Payment mechanisms, which provide secure and easy payment methods. }\end{array}$ \\
\hline Management & & $\begin{array}{l}\text { Business strategy, which shifts from short-tail thinking to long-tail thinking, } \\
\text { subdivides user community and explores niche brand community to find niche } \\
\text { products. } \\
\text { Social objectives, which move from economic development problems to } \\
\text { outcomes of social and economic significance, such as job placement which } \\
\text { provide social job by observing participants who show their abilities in } \\
\text { product design process. } \\
\text { Operation, which should change business patterns and shift from online } \\
\text { business to O2O to further improve user experience under offline. }\end{array}$ \\
\hline
\end{tabular}

\section{Conclusion}

Based on literature review of foreign design science and social commerce, we introduce design framework application environment changes and social commerce design models. By comparing information model and social commerce design model, we propose a new social commerce design model and summarize general design characteristics of social commerce, including individual, conversation, community, commerce and management. There are still some limitations in our research. Practical significance of our new model needs to be further researched. In the future, social commerce design research opportunities and challenges mainly reflects in two aspects of social distribution, design patterns. Social distribution refers to groups and individuals and structure distribution refers to weather there is a design pattern. 


\subsection{Strengthen Social Distribution}

Groups may increase combination of personal knowledge and environment in which they are situated. When individuals engage in collaborative problem solving, they bring unique ideas and competencies to bear on the problem and facilitate cross-checking of a solution as it unfolds. User shopping behavior shifted from original search to scene, leading to individuals direct spent in their own social or entertainment place. How to design things connected to the Internet scene, meeting the demand of potential user groups? How to transform user shopping habits and induce user buy extra product and service. These will be the key problems faced social commerce design features.

\subsection{Refine Design Patterns}

Design patterns may be regarded as a means of codifying expert knowledge schemas derived from software design practice. Design patterns as external representational media have the potential to evoke cognitive processes relevant to the task at hand, and fill informational gaps to reduce the inherent ambiguity of design problems. Design patterns affect both the quality of the solution and the time taken to solve the problem. How to refine design knowledge to design patterns as reference for designers? How to cooperate with team member to cognize design patterns? How to apply design patterns to specific environment? Future social commerce designers need to consider these problems.

\section{Reference}

Constantinides E., \& Fountain, S. J. (2008). Web 2.0: Conceptual foundations and marketing issues. Journal of Direct, Data and Digital Marketing Practice, 9(3), 231-244.

Cyr, D. (2014). Return visits: a review of how Web site design can engender visitor loyalty. Journal of Information Technology, 29(1), 1-26.

DA COSTA TEVES T. (2013). Social commerce: conceptual model and customer perception.

Fisher, E. (2010). Social design. Facebook Developers. Available atdevelopers.facebook.com/socialdesign

Goes, P. B. (2014). Editor's comments: design science research in top information systems journals. MIS Quarterly, 38(1), iii-viii.

Gonçalves Curty R, Zhang P. (2013). Website features that gave rise to social commerce: a historical analysis. Electronic Commerce Research and Applications, 12(4), 260-279.

Grange, C, Benbasat, I. (2010). Online social shopping: The functions and symbols of design artifacts. Proceedings of System Sciences (HICSS), 2010 43rd Hawaii International Conference on. IEEE, 1-10.

Gregor, S., \& Hevner, A. R. (2013). Positioning and presenting design science research for maximum impact. MIS Quarterly, 37(2), 337-356.

Hajli, M. N. (2014). The role of social support on relationship quality and social commerce. Technological Forecasting and Social Change, 87, 17-27.

Helander M G, Khalid H M. (2000). Modeling the customer in electronic commerce. Applied Ergonomics, 31(6), 609-619.

Huang, Z., Benyoucef, M. (2013). From e-commerce to social commerce: A close look at design features. Electronic Commerce Research and Applications, 12(4), 246-259.

Huang, Z., Benyoucef, M. (2014). User preferences of social features on social commerce websites: An empirical study. Technological Forecasting and Social Change.

Huang Z, Yoon,S.Y., \& Benyoucef, M. (2012). Adding Social Features to E-commerce. Proceedings of the Conference on Information Systems Applied Research ISSN, 2167-1508.

Jones, D., \& Gregor, S. (2007). The anatomy of a design theory. Journal of the Association for Information Systems, $8(5), 1$.

Koch, G., Füller J., \& Brunswicker, S. (2011). Online crowdsourcing in the public sector: How to design open government platforms. Online Communities and Social Computing. Springer Berlin Heidelberg, 203-212.

Leitner P, Grechenig T. (2009). Scalable social software services: towards a shopping community model based on analyses of established web service components and functions. System Sciences, 2009. HICSS'09. 42nd Hawaii International Conference on. IEEE, 1-10.

Mangalaraj, G., Nerur, S., Mahapatra, R. K, et al. (2014). Distributed cognition in software design: an experimental investigation of the role of design patterns and collaboration. MIS Quarterly, 38(1), 249-274.

March, S. T., \& Smith, G. F. (1995). Design and natural science research on information technology. Decision support systems, 15(4), 251-266.

Markus, M. L., Majchrzak, A, Gasser, L. (2002). A design theory for systems that support emergent knowledge processes. Mis Quarterly, 179-212.

Matera, M., Costabile, M. F., Garzotto, F., et al. (2002). SUE inspection: an effective method for systematic usability evaluation of hypermedia. Systems, Man and Cybernetics, Part A: Systems and Humans, IEEE Transactions on, 32(1), 93-103. 
Peffers, K., Tuunanen, T., Rothenberger, M. A., et al. (2007). A design science research methodology for information systems research. Journal of management information systems, 24(3), 45-77.

Simon, H. A. (1969). The sciences of the artificial. MIT press.

Socialmachinery. (2012). The emergence of the Crowdsumers. Retrieved from $\mathrm{http}: / / \mathrm{www}$. Socialmachinery.com/the-emergence-of-the-crowdsumers/

Study Says Web Shoppers Crave 'Social' Experience. Retrieved June 4, 2007, from http://www.adweek.com/news/advertising/study-says-web-shoppers-crave-social-experience-89219

Sundararajan A, Provost F, Oestreicher-Singer G, et al. (2013). Research Commentary-Information in Digital, Economic, and Social Networks. Information Systems Research, 24(4), 883-905.

The five data that social media affects buying behavior. Retrieved Augest 12, 2013, from http://www.socialbeta.com/articles/5-stats-about-how-social-media-influences-purchase-behaviour.html

Von Alan, R. H, March, S. T, \& Park J, et al. (2004). Design science in information systems research. MIS quarterly, 28(1), 75-105.

Wang C, Zhang P. (2012). The evolution of social commerce: The people, management, technology, and information dimensions. Communications of the Association for Information Systems, 31(5), 1-23.

We are social. (2014). The global social media, digital and mobile data business insight. Retrieved February 13, 2014, from http://www.199it.com/archives/194540.html

Why social media counts when it comes to FMCG. Retrieved June 11, 2012, from http://wallblog.co.uk/2012/06/11/why-social-media-counts-when-it-comes-to-fmcg-infographic/

Yahoo! Social commerce via the Shoposphere and pick lists. Retrieved November 14, 2005, from http:// www. ysearchblog.com/social.commerce.via.the.shoposphere. pick.lists

Zhang, P., \& Benjamin, R. I. (2007). Understanding information related fields: A conceptual framework. Journal of the American Society for Information Science and Technology, 58(13), 1934-1947.

Zhang P, Zhou L, Zimmermann H D. (2013). Advances in Social Commerce Research: Guest Editors' Introduction. Zhang, P., Zhou, L., \& Zimmermann, H.-D.(2013). Advances in social commerce research: guest editors' introduction. Electronic Commerce Research and Applications, 12(4), 221-223.

\section{(cc) $\mathrm{BY}$}

This work is licensed under a Creative Commons Attribution 3.0 License. 